\title{
Design, manufacture and initial tests of a drug-eluting coronary stent
}

\author{
Arturo Abundes-Velasco, ${ }^{1}$ Jorge Padilla-Ibarra, ${ }^{2}$ Gian M. Jiménez-Rodríguez, ${ }^{2}$ Julio I. Farjat-Pasos, ${ }^{2}$ \\ Eduardo A. Arias-Sánchez, ${ }^{2}$ Félix Damas-de los Santos, ${ }^{2}$ Marco A. Martínez-Ríos, ${ }^{2}$ \\ Francisco J. Molina-Méndez, ${ }^{3}$ Tomás E. Sánchez-Pérez, ${ }^{1}$ Marco M. Arai-Ito, ${ }^{1}$ \\ Sebastián Aceves-Díaz González, ${ }^{1}$ David A. Rodríguez-Parra, ${ }^{1}$ Alberto Aranda-Fraustro, ${ }^{4}$ \\ Felipe A. Masso-Rojas, ${ }^{5}$ Ramsés Galaz-Méndez ${ }^{6}$ and Marco A. Peña-Duque ${ }^{1 *}$
}

'Instituto Nacional de Cardiología "Ignacio Chávez", Technological Development and Innovation Department; 'Instituto Nacional de Cardiología "Ignacio Chávez", Interventional Cardiology Department; ${ }^{3}$ Instituto Nacional de Cardiología "Ignacio Chávez", Cardiovascular Anesthesiology Department; "Instituto Nacional de Cardiología "Ignacio Chávez", Pathology Department; ${ }^{5}$ Instituto Nacional de Cardiología "Ignacio Chávez", Physiology Department; ${ }^{6}$ Instituto Tecnológico y de Estudios Superiores de Monterrey, Campus Mexico City, Biomedical Engineering. Mexico City, Mexico

\begin{abstract}
Introduction: A drug-eluting coronary stent is being developed at the National Institute of Cardiology of Mexico for the treatment of ischemic heart disease. Objective: To establish the best animal model for the tests, to show the advances in the drug-eluting stent prototype, to assess two drugs' antiproliferative activity and histological results. Method: Smooth muscle cell culture tests were performed in order to assess sirolimus and paclitaxel antiproliferative properties. The drugs were encapsulated inside the polymeric matrix of the stents. Rabbits and pigs were used as animal models. Results: Sirolimus and paclitaxel showed an inhibitory effect, which was higher for the latter. Infrared spectroscopy and light and optical microscopy showed that the drug/polymer layer properly adhered to the stent. At a four-week follow-up, both animal models showed satisfactory clinical evolution and adequate histological response, although the porcine model was shown to be more suitable for future protocols. Conclusions: Preliminary tests of the drug-eluting stent provided bases for the development of a study protocol with an adequate number of pigs and with clinical angiographic and histopathological three-month follow-up.
\end{abstract}

KEY WORDS: Drug-eluting coronary stent. Sirolimus. Coronary stent.

\section{Diseño, fabricación y pruebas iniciales de una endoprótesis coronaria liberadora de fármaco}

\section{Resumen}

Introducción: En el Instituto Nacional de Cardiología de México se desarrolla una endoprótesis (stent) coronaria liberadora de fármacos para el tratamiento de la cardiopatía isquémica. Objetivo: Establecer el mejor modelo animal para las pruebas, mostrar los avances en el prototipo del stent liberador de fármacos, evaluar la actividad antiproliferativa de dos fármacos y los resultados histológicos. Método: Se realizaron cultivos de células de músculo liso para evaluar las propiedades antiproliferativas de sirolimus y paclitaxel. Los fármacos fueron encapsulados en el interior de la matriz polimérica de los stents. Se emplearon conejos y cerdos como modelos animales. Resultados: Sirolimus y paclitaxel mostraron efecto inhibitorio, mayor 
en el segundo. La espectroscopia infrarroja y la microscopia óptica y electrónica mostraron que la capa del polímero con el fármaco se adhería adecuadamente al stent. A las cuatro semanas de seguimiento, ambos modelos animales mostraron evolución clínica satisfactoria y adecuada respuesta histológica, si bien el modelo porcino resultó más conveniente para protocolos futuros. Conclusiones: Las pruebas preliminares del stent liberador de fármaco brindó bases para desarrollar el protocolo con un número adecuado en cerdos y con seguimiento clínico angiográfico e histopatológico a tres meses.

PALABRAS CLAVE: Endoprótesis coronaria liberadora de fármaco. Sirolimus. Stent coronario.

\section{Introduction}

The importance of drug-eluting stents (DES) in the management of acute or chronic ischemic heart disease is unquestionable ${ }^{1-3}$ First-generation DES (Cypher $^{\mathrm{TM}}$ and Taxus $^{\mathrm{TM}}$ ) had a spectacular effect on clinical practice, mainly due to the drastic reduction in restenosis: from $30 \%$ or more with conventional stents, it decreased to less than $6 \%{ }^{4,5}$ However, in the long term, the risk of thrombosis remained ${ }^{6}$ and the presence of neo-atherosclerosis started being reported.?

Advances in the technology of current second-generation DES have been important: from the material for its manufacture, design, coating and polymer type, to the type of anti-proliferative drug. ${ }^{8}$ Among the improvements, the numerous metals and alloys that have been studied stand out, which provide greater radial force or displacement to the devices. Currently, the most widely used is the cobalt-chromium alloy, which has allowed to decrease the thickness of the stent walls and, consequently, the frequency of restenosis. Another innovation is bio-absorbable polymers, which are applied to the outer surface of the device ${ }^{9}$ In a recent publication, where a DES coated with a biodegradable polymer that releases sirolimus was compared with a DES coated with non-biodegradable polymer that releases everolimus, no differences were shown at 12 months of follow-up. ${ }^{10}$

There is no doubt that progresses and improvements will continue and probably the greatest efforts will be aimed at achieving, in addition to the anti-proliferative effect, a faster and more complete endothelialization of the treated surface, in order to prevent not only restenosis but also thrombosis, use of long-term dual antiplatelet therapy and neo-atherosclerosis.

For several years, efforts have been made to develop stents in Mexico. ${ }^{11-13}$ Since 2014, the National Institute of Cardiology started the development of a bare metal stent (INC-01) with two models, which have undergone finite element computational tests, as well as mechanical and biological tests, with satisfactory results; ${ }^{14,15}$ as a consequence, the protocol in human beings has been initiated.

In order to continue with this project, developing a DES (INC D), using the same alloy as for INC-01, was planned. This initial report describes the advances, the anti-proliferative evaluation of several drugs, the establishment of the animal model and histological evaluation of the results.

\section{Method}

In the Physiology Department of the National Institute of Cardiology, tests were carried out on the anti-proliferative properties of two drugs, paclitaxel and sirolimus, in smooth muscle cell cultures. The effect of the drugs was assessed by cytometry in smooth muscle cell cultures, which were stained with CellTrace ${ }^{\mathrm{TM}}$ (Thermo Fisher); doses of 15, 50 and $100 \mathrm{nM}$ were used with paclitaxel and equimolar doses with sirolimus.

The DES were manufactured by the GSE Biomedical company and the National Institute of Cardiology with the support of the National Council of Science and Technology. The following drugs were used:

- Sirolimus (Vetranal ${ }^{\circledR}$, analytical grade), from Sigma-Aldrich.

- Paclitaxel ( $\geq 95 \%$, HPLC grade), from Sigma-Aldrich.

Poly-lactic acid was used, at a poly-L-lactic acid:poly-D-lactic acid ratio of 20:80. The study was carried out on 18 INC-01 cobalt-chromium stents.

The polymer coating was sprayed using a 4-12 V 113 $\mathrm{kHz}$ ultrasonic actuator at $4.5 \mathrm{~cm}$ from the substrate, with poly-lactic acid solutions at $1.0 \%$ w/v concentration.

The drugs were integrated encapsulated inside the polymer matrix at a drug-polymer weight ratio of $20: 80$, following the concentrations recommended in the literature $\mathrm{e}^{16,17}$

Of the 18 stents, six were coated with the sirolimus preparation (INC D1) and six with the paclitaxel preparation (INC D2), maintaining the recommended amount of $150 \pm 10 \mu \mathrm{g}$ of drug per stent. All the materials were autoclaved. 
Stent coating was assessed using digital light microscopy and infrared spectroscopy to confirm the absence of interaction between the polymer matrix and the encapsulated drug; in addition, a transmission electron microscopy assay was performed to calculate the thickness of the coating.

The DES preparation and assembly was carried out in an area specially designed for the assembly of medical devices, with controlled environment and in sterile conditions. Angioplasty balloons (generic) were acquired: two $3.0-\mathrm{mm}$ diameter $\times 20 \mathrm{~mm}$-length and two $3.5-\mathrm{mm}$ diameter $\times 20-\mathrm{mm}$ length, on which the stents were placed using special equipment (pressing device); the polymer film was protected with Teflon paper. Fixation and centering of the stent in the balloon were verified. The profile of the mounted stent was measured using a Vernier caliper and the surface was checked by stereoscopic microscopy. Two paclitaxel stents were mounted on a $3.0-$ and a $3.5-\mathrm{mm}$ diameter balloon catheter, respectively. The same procedure was followed with two stents with sirolimus.

The devices were individually packaged and sealed, identifying the drug and balloon size. Sterilization was carried out using gas.

\section{Leporid model}

Two rabbits were used for each of the three vascular access techniques that were tested: carotid dissection, femoral dissection, and percutaneous puncture, which were difficult to perform, required much time, and had local complications. Vascular access was carried out without complications only in one specimen by percutaneous puncture, in which the INC D1 stent (sirolimus) was implanted. It was a New Zealand male rabbit (Oryctolagus cuniculus), four months old and weighing $3.5 \mathrm{~kg}$, obtained from the Center for Teaching, Research and Extension in Poultry Production of the National Autonomous University of Mexico (UNAM - Universidad Nacional Autónoma de México), after authorization by the National Institute of Cardiology scientific and animal handling committee. The rabbit received aspirin and clopidogrel as premedication and was sedated one hour before the surgical procedure.

Puncture of the left femoral artery was performed using the Seldinger technique and a 4-Fr caliber introducer catheter was placed. 400 units of heparin were administered. A 0.014 " coronary guidewire was directed to the aortic arch and then the $3.5 \times 18 \mathrm{~mm}$
INC D1 stent (sirolimus) was introduced, which was implanted in the abdominal aorta at 16 atmospheres, with a stent/aorta ratio of 1.2/1 (slightly overexpanded). Adequate stent expansion was corroborated with a control aortography. Fluoroscopy time was 12 minutes and $10 \mathrm{~mL}$ of contrast medium (Hexabrix ${ }^{\mathrm{TM}}$, Guerbet) were used.

During four weeks of follow-up, aspirin $50 \mathrm{mg} /$ day and clopidogrel $7.5 \mathrm{mg} /$ day were administered, both orally. At follow-up conclusion, euthanasia was carried out under deep sedation with $1 \mathrm{mEq} / \mathrm{kg}$ of potassium chloride solution. Subsequently, autopsy of the heart and sectioning of the thoracic-abdominal aorta and manual removal of the stent were carried out. $5-\mu \mathrm{m}$ sections of the samples were made, which were fixed in $10 \%$ formalin. Histopathological examination was performed with hematoxylin-eosin and Masson stains, and morphometric analysis of the treated site was carried out at the Pathology Department of the National Institute of Cardiology.

\section{Porcine model}

A single specimen was used, which was successful: a three-month-old, 46-kg female Yorkshire pig, obtained from the UNAM Center for Teaching, Research and Extension in Swine Production, after authorization by the National Institute of Cardiology scientific and animal management committee. Premedication was administered with $100 \mathrm{mg}$ aspirin and $300 \mathrm{mg}$ clopidogrel.

After sedation, asepsis and antisepsis of the right femoral region and local anesthesia with $2 \%$ simple lidocaine, puncture of the right femoral artery was performed; using the Seldinger technique, a femoral 6-Fr-caliber introducer catheter was placed. Subsequently, a 0.035 " Teflon-coated guidewire was inserted for the displacement of a 6-FR-caliber Judkins-type right guidewire catheter. A cannula was installed in the right coronary artery, to introduce a 0.014 " guidewire into the distal segment and advance the $3.5 \mathrm{x}$ 18-mm INC D2 stent (paclitaxel), which was implanted in the middle segment of the right coronary artery at a pressure of 18 atmospheres, with a stent/coronary ratio of 1.2/1. Subsequently, the balloon was insufflated to corroborate adequate expansion of the stent. 80 $\mathrm{mL}$ of contrast medium (Hexabrix) were used. Fluoroscopy time was 12 minutes. 7000 units of unfractionated heparin were used.

During the four weeks of follow-up, $100 \mathrm{mg} /$ day of aspirin and $75 \mathrm{mg} /$ day of clopidogrel were orally 


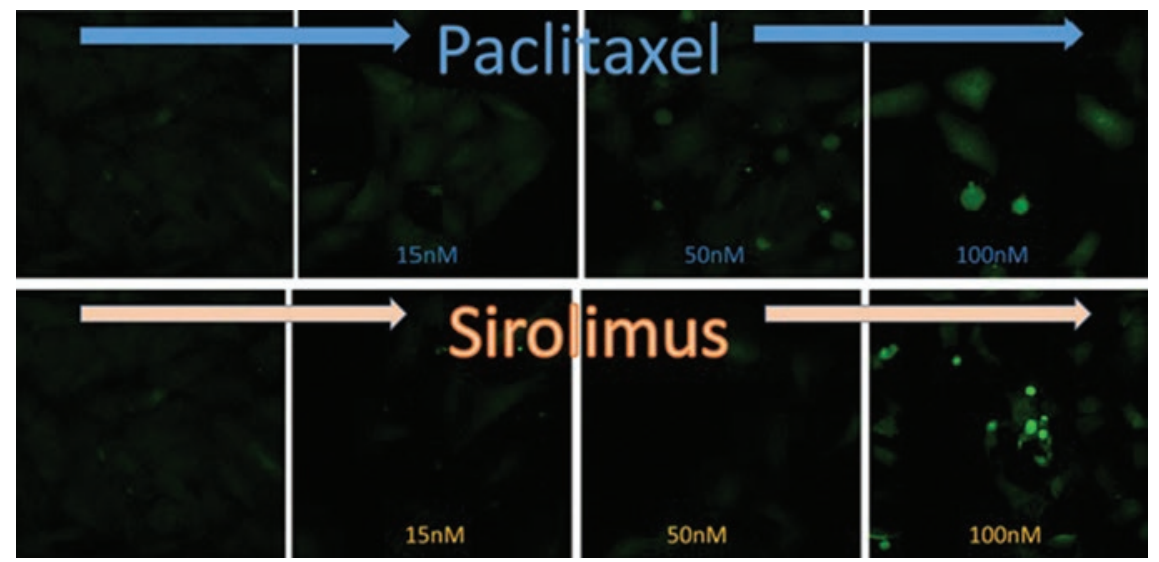

Figure 1. Cell staining using the CellTrace method: from left to right, the decrease in cell division with paclitaxel can be observed. Increased intensity shows that the cells divided fewer times; dye retention indicates anti-proliferative activity.

administered. At the end of this period, euthanasia was carried out under deep sedation with $1 \mathrm{mEq} / \mathrm{kg}$ of potassium chloride solution, followed by autopsy of the heart and dissection of the coronary arteries, fixation with $10 \%$ formalin, treatment with electrodeposition of the INC D2 stent ${ }^{18}$ and sections with a $5-\mu \mathrm{m}$ microtome. For histopathological study, hematoxylin-eosin and Masson stains were used. The morphometric analysis of the treated coronary artery was carried out at the Institute's Pathology Department.

\section{Results}

\section{Of the evaluated anti-proliferative effect}

Using CellTrace staining, the number of cells was observed to be lower as the dose of the drug increased, but intensity of the dye was higher, which suggests lower cell division and, therefore, greater staining of the dye, which indicates anti-proliferative activity of both drugs.

With the same sirolimus doses, although the cells showed higher dye intensity, there was a larger number of cells than in the paclitaxel evaluation, the anti-proliferative effect of which appears to be superior to that of sirolimus at equimolar doses (Fig. 1).

\section{Polymer/drug coating}

Integrity of the stents' poly-lactic acid film was verified by photomicrography.

The DES were subjected to transmission electron microscopy. The polymeric coating with paclitaxel and sirolimus had a thickness of 0.600 and $0.130 \mu \mathrm{m}$, respectively (Fig. 2).

The absence of new signals on infrared spectroscopy indicated that no new functional groups were formed as a product of a reaction between the polymeric matrix and the encapsulated drug.

\section{Leporid model}

The intervention was considered to be successful. Adequate luminal diameter after implantation was confirmed by angiography, with normal contrast medium displacement and with no evidence of dissection, contrast material leakage or intravascular thrombus; in addition, anatomy of the treated site and secondary vessels were preserved. There were no complications with the implantation of the INC D1 stent in the rabbit abdominal aorta, and neither were there adverse events.

Before this model, two implantations were unsuccessfully tried, the first one by carotid surgical dissection and the second by inguinal dissection of the femoral carotid.

\section{Porcine model}

The intervention was successful, without complications or adverse events. After implantation, angiography confirmed adequate expansion of the artery, normal displacement of contrast medium, with no evidence of dissection, contrast material leakage or intravascular thrombus; anatomy of the treated site and secondary vessels were preserved. This model was more appropriate and more similar to human anatomy and physiology. 

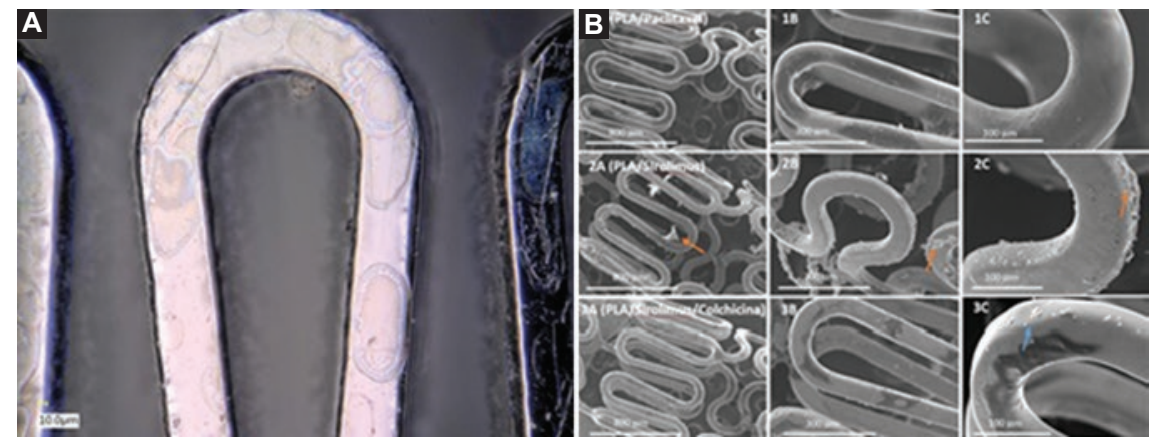

Figure 2. A) Electron microscopy of the polymer coating on the surface of the cobalt-chromium stent. B) Scanning electron microscopy at three magnifications (75, 200 and $500 x$ ): $1 A, 1 B$ and $1 C$, paclitaxel-releasing polymer; $2 A, 2 B$ and $2 C$, sirolimus-releasing polymer.

\section{Stent implantation technical evaluation}

Percutaneous implantation was satisfactory in both models: DES release, displacement, implantation and expansion were adequate, as well as balloon-releasing catheter removal and angiographic analysis. Furthermore, preserving the collateral vessels was possible, with normal final blood flow.

\section{Follow-up and histopathological results}

Both models showed adequate weight gain during the four-week follow-up, without the presence of adverse events.

The rabbit aorta was longitudinally dissected for stent extraction. Neo-intimal proliferation and data consistent with inflammation or bleeding were not observed. The INC D1 stent showed high capacity to inhibit cell proliferation and inflammation. The INC-D2 stent was removed by cross section of the pig coronary artery. The stent struts were observed to be dark brown in color, in oval or round arrangement in the intima-smooth muscle transition zone. There was accentuated proliferation of the intima on the stent. The struts were partially attached to the muscle layer, which was slightly sclerosed, and were projected towards the fibrous intima, with scarce lipids in the form of drops or circumferences. The INC D2 stent showed no power to inhibit neointimal proliferation with the drug concentration used in the porcine model (Fig. 3).

\section{Discussion}

Expenditure on research and experimental development is an indicator and, at the same time, a promoter of economic growth in different countries. Much of the economy of developed countries is based on scientific and technological knowledge

In the United States, $2.79 \%$ of the gross domestic product is assigned to research and technological development, while the average in Latin America is $0.62 \%$, and in Mexico, $0.44 \%$ is invested. ${ }^{19,20}$ To approach more competitive figures, there is no doubt that huge efforts are needed in our country, involving government and private initiative participation.

With the support of GSE Biomedical and the National Council of Science and Technology, at the National Institute of Cardiology "Ignacio Chávez", the project of a DES (called INC D) was started. Given that it involves state-of-the-art technology and that proper selection of each component and resource of the project is required, the development path described in this manuscript was established. The obtained results are the basis for preparing the next research project: the animal protocol with the INC D stent, with a follow-up of three and six months for a final angiographic and histopathological study.

Based on this initial exploration, we conclude that we will continue with the cobalt-chromium platform, which is an alloy that has excellent radial strength, it is radiopaque and can be subjected to magnetic resonance imaging, allowing its visualization by conventional fluoroscopy. ${ }^{21}$

The protocol with INC D will be carried out with a biodegradable polymer coating (poly-lactic acid) on the external surface of the device.

Some thermoplastic polyesters such as poly-glycolic acid (PGA) and poly-lactic-coglycolic acid (PLGA) have been shown to be biodegradable materials suitable for medical applications. Owing to its methyl group, poly-lactic acid is more hydrophobic than PGA and PLGA, and it is therefore more suitable for 

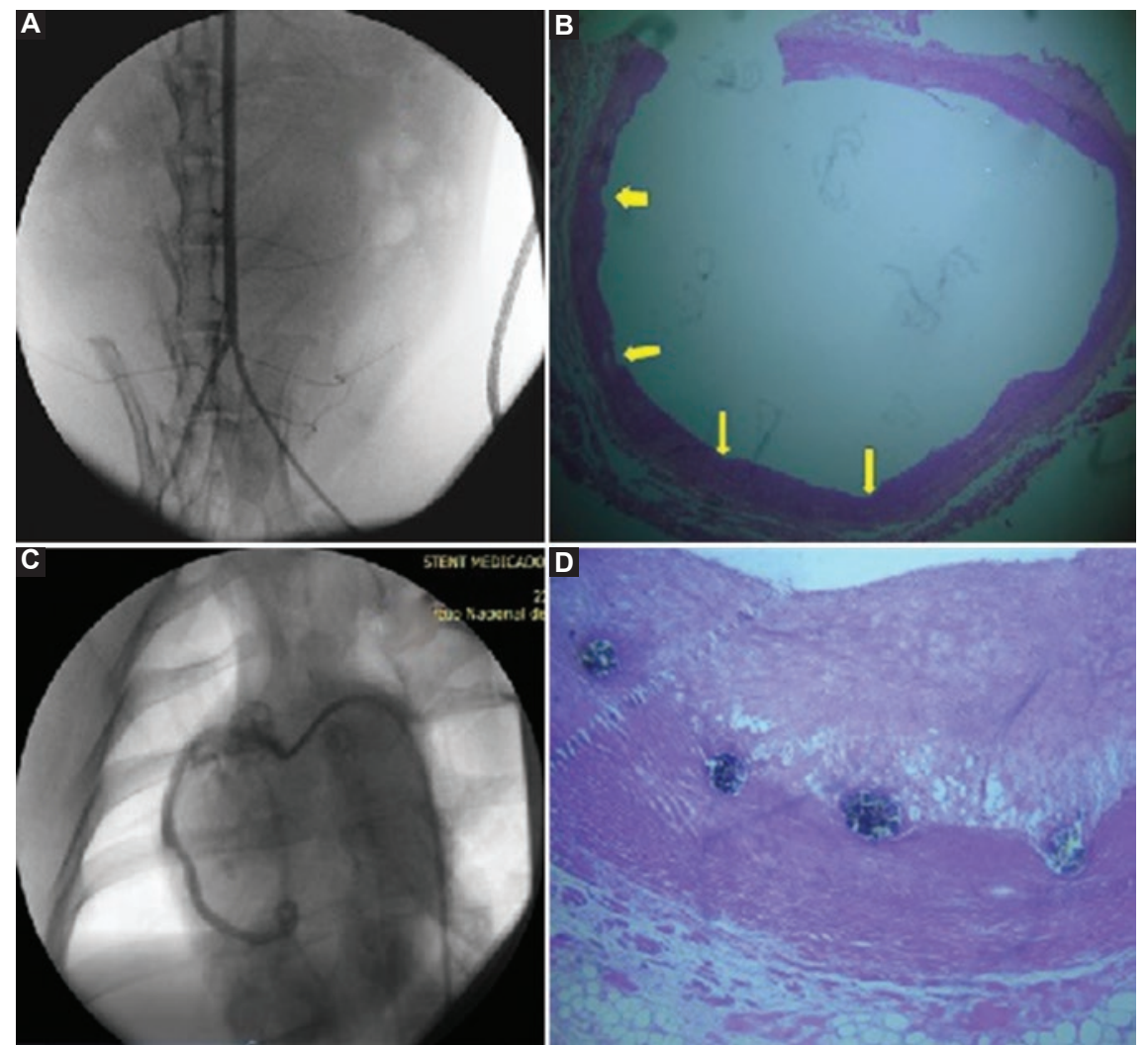

Figure 3. Angiography and histopathological images of the animal models. A and B) Leporid model in which percutaneous left femoral access was carried out. The angiography shows vascular integrity of the aorta with the INC-D1 stent (sirolimus) and the photomicrography of the rabbit aorta shows the notches (yellow arrows) left by the INC-D1 stent (sirolimus) struts, without neointimal proliferation . C and D) Porcine model. Angiographic image was obtained after implantation of the INC-D2 stent (paclitaxel) in the middle third of the pig's coronary artery. In the photomicrography of the pig's right coronary artery in cross section with the INC-D2 stent (paclitaxel), two struts are observed that are partially attached to the slightly sclerosed muscular layer and project to the fibrous intima with scarce lipids in the form of drops or circumferences (40 $\mathrm{x}$ ).

encapsulating substances with low or no water solubility, such as sirolimus. ${ }^{9}$ Poly-lactic acid biodegradation occurs by hydrolysis, whereby the released lactic acid is eliminated by the body through the Krebs cycle in the form of carbon dioxide and water, which are non-toxic metabolic products. ${ }^{9}$

Coating only of the DES outer surface is intended to inhibit cell growth and neointimal proliferation only on the vessel wall in contact with the stent struts and, on the other hand, to favor for the luminal surface to be more easily colonized by healthy endothelium. ${ }^{22}$

The anti-proliferative drug chosen for INC $D$ will be sirolimus, due to its important immunosuppressive activity that blocks protein synthesis and cell cycle, and because it has shown higher effectivity against restenosis. Immunosuppressive macrolides are currently the most widely accepted for incorporation to drug-eluting stents. ${ }^{8}$

The animal model will be porcine, since there is more evidence in the international literature for the assessment of DES in this species, and because, technically, the procedure is simpler and there is less morbidity and mortality during implantation. To compensate for the drawback of the rapid increase in size and weight of the animals during follow-up, ${ }^{23,24}$ the stent diameter will be slightly oversized with regard to the diameter of the selected coronary segment. ${ }^{25}$

Histological evaluation will be carried out by modified electrodeposition, ${ }^{18}$ because it is a faster and lower-cost method than fixation with methacrylate; it also allows intact preservation of tissues.

\section{Conclusions}

The experimentation phase will be started with an adequate number of pigs based on drug assessment, feasibility to produce the vascular stent, the surgical procedure and the most appropriate specimen. If the results are satisfactory, the clinical protocol will follow. 
The importance of the technological development of devices made in Mexico is highlighted, which will allow independence and competitiveness of the country.

\section{Conflict of interests}

The authors declare that they have no conflicts of interest.

\section{Funding}

The authors did not receive any sponsoring for carrying out this article. The described project was carried out with the support of the GSE Biomedical company and National Institute of Cardiology's own resources.

\section{Ethical disclosure}

Protection of people and animals The authors declare that the procedures followed were carried out in accordance with the ethical standards of the responsible human experimentation committee, the World Medical Association and the Declaration of Helsinki.

Confidentiality of data The authors declare that no patient data appear in this article.

Right to privacy and informed consent The authors declare that no patient data appear in this article.

\section{References}

1. Windecker S, Kolh P, Alfonso F, Collet JP, Cremer J, Falk V, et al. 2014 SC/EACTS Guidelines on myocardial revascularization: The Task Force on Myocardial Revascularization of the European Society of Cardiology (ESC) and the European Association for Cardio-Thoracic Surgery (EACTS) developed with the special contribution of the European Association of Percutaneous Cardiovascular Interventions (EAPCI). Eur Heart J. 2014;35:2541-2619.

2. Levine GN, Bates ER, Blankenship JC, Bailey SR, Bittl JA, Cercek B, et al. $2015 \mathrm{ACC} / \mathrm{AHA} / \mathrm{SCAl}$ focused update on primary percutaneous coronary intervention for patients with ST-elevation myocardial Infarction: An update of the 2011 ACCF/AHA/SCAI guideline for percutaneous coronary intervention and the 2013 ACCF/AHA guideline for the management of ST-elevation myocardial infarction: A report of the American College of Cardiology/American Heart Association Task Force on Clinical Practice Guidelines and the Society for Cardiovascular Angiography and Interventions. Catheter Cardiovasc Interv. 2016;87:1001-1019.
3. Montalescot G, Sechtem U, Achenbach S, Andreotti F, Arden C, Budaj A et al. 2013 ESC guidelines on the management of stable coronary artery disease: The Task Force on the management of stable coronary artery disease of the European Society of Cardiology. Eur Heart J. 2013;34:2949-3003.

4. Stone GW, Ellis SG, Colombo A, Grube E, Popma JJ, Uchida T, et al. Longterm safety and efficacy of paclitaxel-eluting stents final 5-year analysis from the TAXUS Clinical Trial Program. JACC Cardiovasc Interv. 2011;4:530-342.

5. Sousa JE, Costa MA, Abizaid A, Feres F, Seixas AC, Tanajura LF, et al. Four-year angiographic and intravascular ultrasound follow-up of patients treated with sirolimus-eluting stents. Circulation. 2005;111:2326-2329.

6. Stone GW, Moses JW, Ellis SG, Schofer J, Dawkins KD, Morice MC, et al. Safety and efficacy of sirolimus- and paclitaxel-eluting coronary stents. N Engl J Med. 2007;356:998-1008.

7. Ueda $Y$, Matsuo K, Nishimoto $Y$, Sugihara R, Hirata A, Nemoto T, et al. In-Stent yellow plaque at 1 year after implantation is associated with future event of very late stent failure: The DESNOTE Study (detect the event of very late stent failure from the drug-eluting stent not well covered by neointima determined by angioscopy). JACC Cardiovasc Interv. 2015;8:814-821

8. Lee DH, de la Torre-Hernandez JM. The newest generation of drug-eluting stents and beyond. Eur Cardiol. 2018;13:54-59.

9. Parker T, Davé V, Falotico R. Polymers for drug eluting stents. Curr Pharm Des. 2010;16:3978-3988.

10. De Winter RJ, Katagiri Y, Asano T, Milewski KP, Lurz P, Buszman P, et al. A sirolimus-eluting bioabsorbable polymer-coated stent (MiStent) versus an everolimus-eluting durable polymer stent (Xience) after percutaneous coronary intervention (DESSOLVE III): A randomised, single-blind, multicentre, non-inferiority, phase 3 trial. Lancet. 2018;391:431-440.

11. Abundes AV, Quintana PG, Navarro RJ, Ledesma VM, Autrey CA, SoIorio MS, et al. Estudio piloto preliminar en humanos con la prótesis endovascular (stent saq). Resultados inmediatos y a mediano plazo. Arch Cardiol Mex. 2000;70:377-383.

12. Abstracts: Oral and poster presentations. The Society for Cardiac Angiography and Interventions' 24th Annual Scientific Sessions, May 16-19, 2001. Westin Galleria Houston, Texas. Cathet Cardiovasc Intervent. 2001;:53:97-122.

13. Abundes A, Rivera JJ, Arizmendi E, Farell J, Ledesma M, Montoya S. Immediate and long-term results of implantation of the new platinum coronary stent (atlas stent) in patients with coronary artery disease. Rev Esp Cardiol. 2002:55:1205-1208.

14. Abundes A, Romero JL, Sandoval JP, Galaz R, Ulacia P, Peña MA, et al. Diseño y fabricación de un stent coronario e inicio de pruebas en animales de experimentación. Rev Mex Cardiol. 2016;27.

15. Abundes A, Rodríguez E, Custodio P, Romero JL, Gala R, Ulacia P, et al. Experiencia fase animal del STENT coronario INC. Arch Cardiol Mex. 2017:87:79.

16. Waugh J, Wagstaff AJ. The paclitaxel (TAXUS)-eluting stent: A review of its use in the management of de novo coronary artery lesions. Am J Cardiovasc Drugs. 2004;4:257-268.

17. Vishnevetsky D, Patel P, Tijerino H, Gandhi PJ. Sirolimus-eluting Coronary Stent. Am J Health Syst Pharm. 2004;61:449-456.

18. Zúñiga-Ayala $M$, Juárez-Alvarado $O$, Aranda-Fraustro $A$, Velázquez-Espejel R, Becerra-Luna B, Peña-Duque M. Estudio histopatológico de arteria coronaria, tratada con stent metálico, posterior a la técnica de electrodeposición. Arch Cardiol Mex. 2017;87:81-82.

19. De la Peña L. Ciencia y tecnología en México, país dependiente. Ciencias. 1987:10:38-45.

20. World Bank Group [online]. USA: Research and development expenditure (\% of GDP); 2020.

21. Karanasiou GS, Papafaklis MI, Conway C, Michalis LK, Tzafriri R, Edelman ER, et al. Stents: Biomechanics, biomaterials, and insights from computational modeling. Ann Biomed Eng. 2017;45:853-872.

22. Kozuma K. Has the development of drug-eluting stents ended with limus-eluting stents? Circ J. 2018:82:330-331.

23. Suzuki $Y$, Yeung AC, Ikeno F. The representative porcine model for human cardiovascular disease. J Biomed Biotechnol. 2011;2011:195483.

24. Goodman SL. Sheep, pig, and human platelet-material interactions with model cardiovascular biomaterials. J Biomed Mater Res. 1999;45:240-250.

25. Schwartz RS, Edelman E, Virmani R, Carter A, Granada JF, Kaluza GL, et al. Drug-eluting stents in preclinical studies: updated consensus recommendations for preclinical evaluation. Circ Cardiovasc Interv. 2008:1:143-153. 